\title{
Perancangan Sistem Informasi Koleksi Benda Seni Ir. Soekarno Pada Istana Negara Berbasis Web
}

\author{
Morina $^{1)}$, Samsoni ${ }^{2)}$ \\ 1,2*Jurusan Teknik Informatika, Fakultas Teknik, Universitas Pamulang \\ Jl. Surya Kencana No.1, Pamulang, Tangerang, Indonesia, 15417 \\ E-Mail: momorinaaa@gmail.com ${ }^{1)}$, samsoni_smart@yahoo.com ${ }^{2)}$
}

\begin{abstract}
ABSTRAK
Yayasan Singgasana Seni adalah salah satu lembaga non profit yang didirikan oleh presiden ke-5 sekaligus anak dari Ir. Sukarno yaitu Megawati Soekarno Putri yang akan diluncurkan Bersamaan dengan penerbitan buku Singgasana Seni dan website www.singgasanaseni.org, yang merupakan salah satu wadah untuk menyimpan dan mengkurasikan koleksi-koleksi karya seni yang di koleksi oleh Presiden pertama indonesia Ir. Soekarno baik yang tersimpan sebagai koleksi keluarga maupun yang tersimpan pada istana negara. Saat Ini ada lebih dari 1300 karya seni yang dikoleksi oleh Presiden Ir. Sukarno, tersebar di enam istana milik Negara Kesatuan Republik Indonesia, koleksi-koleksi tersebut akan dibuatkan buku berjudul Singgasana Seni, buku tersebut terdiri dari 6 seri yang masing-masing bukunya memiliki tema tersendiri. Oleh karena itu penulis berinisiatif untuk membuat sebuah media pustaka digital yang berisi berbagai jenis karya seni yang pernah dikoleksi oleh presiden pertama indonesia yaitu Ir. Sukarno yang tersimpan di Istana Negara menggunakan Django Framework, dengan format seperti buku Lee Man Fong namun bisa dijangkau lebih luas oleh masyarakat melalui website. Dengan adanya website singgasanaseni ini diharapkan akses terhadap Informasi yang berhubungan dengan karya seni terutama koleksi benda seni milik Ir. Sukarno di istana negara menjadi lebih mudah sehingga diharapkan minat masyarakat terhadap seni dan budaya dapat semakin tumbuh sehingga dapat menginspirasi seniman - seniman muda.
\end{abstract}

Kata Kunci - Digital kurasi, python, django framework

\section{Pendahuluan}

Seiring dengan berkembangnya sistem informasi saat ini, banyak sistem informasi pada organisasi yang ingin mencapai tahap sistem informasi secara cepat, relevan dan akurat. Pesatnya pertumbuhan ilmu pengetahuan dan teknologi khususnya di bidang komputer di setiap aspek kehidupan bisa mempermudah pencarian informasi agar akurat dan lebih baik. Penggunaan teknologi komputer dan teknologi komunikasi yang menghasilkan sebuah sistem informasi seperti saat ini, akses informasi kepada masyarakat dapat dipermudah tanpa adanya batasan waktu dan jarak dengan menggunakan jaringan internet, kemudian Computer vision seperti penerapan pengenalan wajah dan pelabelan wajah seperti pada facebook dengan contoh aplikasi Machine Learning (Zailani, Perdananto, \& Sholihin, 2020).

Pesatnya pertumbuhan pengguna internet $\mathrm{di}$ berbagai belahan dunia khususnya negara berkembang. Berdasarkan data yang dihimpun oleh kompas.com, pada februari 2018 ada 143,26 juta jiwa atau 54,67 persen rakyat Indonesia yang telah terhubung internet. Jumlah tersebut mengalami kenaikan sebanyak 13 persen atau 17,3 juta jiwa dibandingkan tahun sebelumnya.

Menurut sebuah Lembaga riset yaitu emarketer yang bergerak pada penelitian bisnis di dunia digital, Indonesia menempati posisi keenam di dunia sebagai negara dengan penggunaan internet terbesar di dunia (Pratomo, 2019).
Banyak hal yang bisa di lakukan dengan internet khususnya pada karya seni, internet dapat digunakan untuk memberikan pengenalan yang lebih baik terhadap karya seni, salah satunya adalah dengan membuat pusataka digital untuk karya-karya seni, Tujuannya adalah memperkenalkan Karya seni tersebut secara lebih luas kepada masyarakat, sehingga mempermudah masyarakat untuk untuk mendapatkan informasi dan referensi tentang karya seni.

Di Indonesia, pustaka digital untuk karya seni salah satunya adalah website ivaa-online.org, website tersebut mengelola arsip elektronik dari kegiatan, ragam karya dan referensi mengenai seniman-seniman visual Indonesia. Hal tersebut membantu untuk mengenalkan seniman-seniman local melalui media online, sehingga mempermudah akses informasi terhadap karya atau seniman tersebut (Yusufhin, 2017). Pendigitalan Karya seni dan menaruhnya pada medium website dapat membantu menyebarkan pemahaman masyarakat terhadap karya seni, karena saat ini masih banyak pengkatalogan karya seni menggunakan pola konvensional dengan buku, salah satu buku yang mendokumentasikan karya seni rupa adalah buku Lee Man Fong, buku tersebut mendokumentasikan karya seni koleksi Ir. Sukarno baik itu lukisan, patung dan kriya. Namun karena jumlah bukunya yang terbatas dan harganya yang cukup mahal membuat buku tersebut sulit untuk di akses (Kompasiana.com, 


\section{Jurnal Ilmu Komputer \& Informatika Л|KI}

2020). Berdasarkan hal tersebut Yayasan Singgasana Seni ingin menggabungkan fungsi dari media konvensional berupa buku dan fungsi dan fungsi media digital berupa website

Yayasan Singgasana Seni adalah salah satu lembaga non profit yang didirikan oleh presiden ke-5 sekaligus anak dari Ir. Sukarno yaitu Megawati Soekarno Putri yang akan diluncurkan Bersamaan dengan penerbitan buku Singgasana Seni dan Website www.singgasanaseni.org, yang merupakan salah satu wadah untuk menyimpan dan mengkurasikan koleksi-koleksi karya seni yang di koleksi oleh Presiden pertama indonesia Ir. Soekarno baik yang tersimpan sebagai koleksi keluarga maupun yang tersimpan pada istana negara. Saat ini ada lebih dari 1300 karya seni yang dikoleksi oleh Presiden Ir. Sukarno, tersebar di enam istana milik Negara Kesatuan Repunlik Indonesia, koleksi-koleksi tersebut akan dibuatkan buku berjudul Singgasana Seni, buku tersebut terdiri dari 6 seri yang masing-masing bukunya memiliki tema tersendiri (Yayasan Singgasana Seni, 2020).

Oleh karena itu, penulis berinisiatif untuk membuat sebuah media pustaka digital yang berisi berbagai jenis karya seni yang pernah dikoleksi oleh presiden pertama indonesia yaitu Ir. Sukarno yang tersimpan di Istana Negara menggunakan Django Framework, dengan format seperti buku Lee Man Fong namun dapat dijangkau lebih luas oleh masyarakat melalui website.

\section{TINJAUAN PUSAKa}

\section{A. Definisi Perancangan}

Perancangan adalah satu langkah untuk memberikan gambaran secara umum kepada manusia atau pengguna tentang sistem yang diusulkan (Saragih, 2015). Perancangan adalah langkah pertama dalam fase pengembangan rekayasa produk atau sistem (Pressman, 2012). Fase ini adalah inti teknis dari proses rekayasa perangkat lunak yang kemudian elemen-elemen dari model analisis dikonversikan. Model itu sendiri merupakan konstruksi melalui parameter spesifik yang diukur baik dalam struktur, bentuk, isi, jumlah dan makna dengan segala keterbatasan (Husain T. , 2019).

\section{B. Definisi Sistem}

Menurut Murdick, R.G (1991), suatu sistem adalah seperangkat elemen yang membentuk kumpulan atau procedure-prosedure/baganbaganpengolahan yang mencari suatu tujuan bagian atau tujuan bersama dengan mengoperasikan data dan/atau barang pada waktu rujukan tertentu untuk menghasilkan informasi dan/atau energi dan/atau barang (Rianto, 2014).

\section{Definisi Informasi}

Informasi dapat didefinisikan sebagai hasil dari pengolahan data dalam suatu bentuk yang lebih berguna dan lebih berarti bagi penerimanya yang menggambarkan suatu kejadian - kejadian (event) yang nyata (fact) yang digunakan untuk pengambilan keputusan (Kusnendi, 2014, hal. 1.19)

\section{Definisi Koleksi}

Kumpulan (gambar, benda bersejarah, lukisan, dan sebagainya) yang sering dikaitkan dengan minat atau hobi objek yang lengkap (KBBI, 2020).

\section{E. Definisi Seni}

Seni adalah karya manusia yang mengomunikasikan pengalaman batin lalu disajikan secara indah atau menarik hingga merangsang timbulnya pengalaman batin pula pada orang lain yang menikmatinya.Namun seni juga dapat menjadi sesederhana peniruan alam dengan segala seginya seperti apa yang diungkapkan oleh Plato. Artinya apa yang dilakukan seni hanyalah melukis pemandangan, menari menirukan gerakan binatang yang elok, bernyanyi mengikutin nada yang disusun melalui rasio alam (fibonaci), dan sebagainya (Thabroni, 2020).

\section{F. Definisi Istana Negara}

Istana Negara merupakan Istana Kepresidenan yang terletak di Jalan Veteran, Jakarta Pusat. Istana Negara juga terletak satu kompleks dengan Istana Merdeka yang letaknya di bagian selatan Istana ini. Dengan total luas keseluruhannya mencapai $68,000 \mathrm{~m}^{2}$, kompleks ini meliputi 3 bangunan penting lainnya seperti Bina Graha, Wisma Negara, dan kantor Kementerian Sekretariat Negara Republik Indonesia (Wikipedia, 2019).

\section{G. Pengertian Website}

Website adalah sering juga disebut Web, dapat diartikan suatu kumpulan-kumpulan halaman yang menampilkan berbagai macam informasi teks, data, gambar diam ataupun bergerak, data animasi, suara, video maupun gabungan dari semuanya, baik itu yang bersifat statis maupun yang dinamis, yang dimana membentuk satu rangkaian bangunan yang saling berkaitan dimana masing-masing dihubungkan dengan jaringan halaman atau hyperlink (Harminingtyas, 2014). Atau definisi website adalah kumpulan dari berbagai macam halaman situs, yang terangkum didalam sebuah domain atau juga subdomain, yang lebih tempatnya berada di dalam WWW (World Wide Web) yang tentunya terdapat di dalam Internet.

Desain situs web dapat dibuat menggunakan aplikasi Adobe Dreamweaver, Microsof FrontPage, Macromedia Firefox, Adobe 


\section{Jurnal Ilmu Komputer \& Informatika JIKI}

Photoshop dan aplikasi lainnya yang dikembangkan sendiri maupun dengan bantuan jasa web designer (Husain \& Budiyantara, 2018). Halaman website biasanya berupa dokumen yang ditulis dalam format Hyper Text Markup Language (HTML), yang bisa diakses melalui HTTP, HTTP adalah suatu protokol yang menyampaikan berbagai informasi dari serverwebsite untuk ditampilkan kepada para user atau pemakai melalui web browser.

\section{Metode Penelitian}

Metode penelitian yang digunakan pada eksperimen ini adalah eksperimen absolut mengarah kepada dampak yang dihasilkan dari eksperimen (Sugiyono, 2016). Penelitian ini pendekatan kualitatif melalui analisis sistem informasi berjalan dengan tujuan mengidentifikasi kebutuhan pengguna yang informasinya diperoleh melalui observasi dan dokumentasi yang diperoleh secara langsung dan situs web. Metode perancangan sistem menggunakan diagram interaksi peran dan sistem (Use Case Diagram) menggambarkan interaksi antara sistem luar (eksternal system) dan pengguna (user). Diagram ini menggambarkan secara grafikal siapa saja yang akan atau dapat menggunakan sistem dan dalam hal apa saja user dapat berhubungan dengan sistem yang ada (Binus University, 2019).

\section{HASIL DAN PEMBAHASAN}

\section{A. Analisis Sistem}

Tahapan analisis ini bertujuan untuk mengidentifikasi permasalahan yang ada di Koleksi Benda Seni Ir. Soekarno pada Istana Negara sehingga dapat memberikan solusi untuk perbaikan maupun pengembangan kearah yang lebih baik dan sesuai dengan kebutuhan pengguna dan perkembangan teknologi berbasis web.

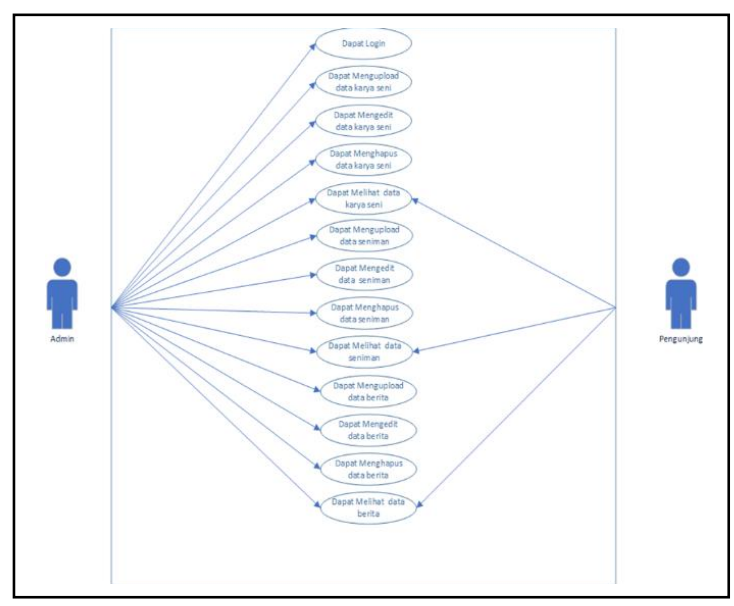

Vol. 1, No. 1, Juli 2020

\section{B. Implementasi Antar Muka}

Hasil use case diagram berdasarkan gambaran sistem berjalan, dituangkan ke dalam implementasi pada setiap antarmuka yang dibuat antara lain:

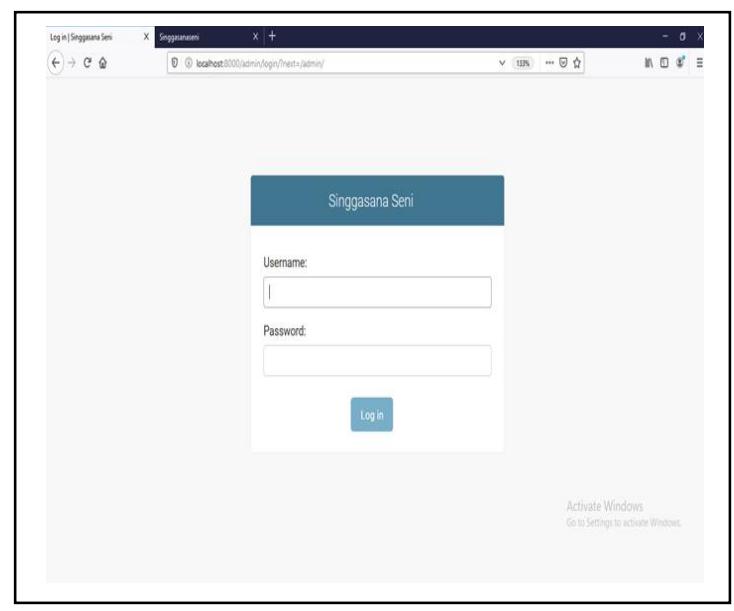

Gambar 2.Tampilan Form Login

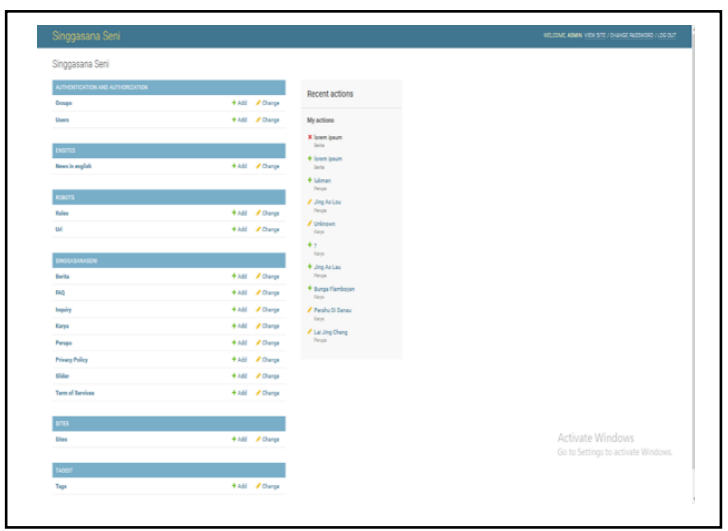

Gambar 3.Tampilan Halaman Admin

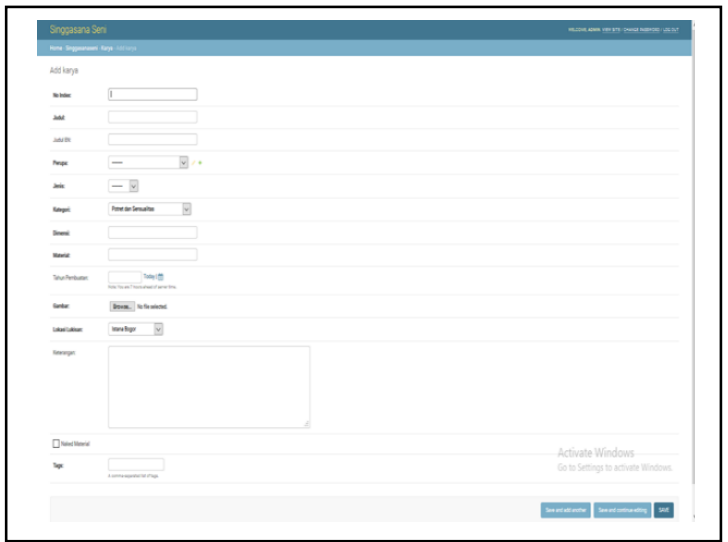

Gambar 4.Tampilan Form Tambah Data

Gambar 1.Use Case Diagram 


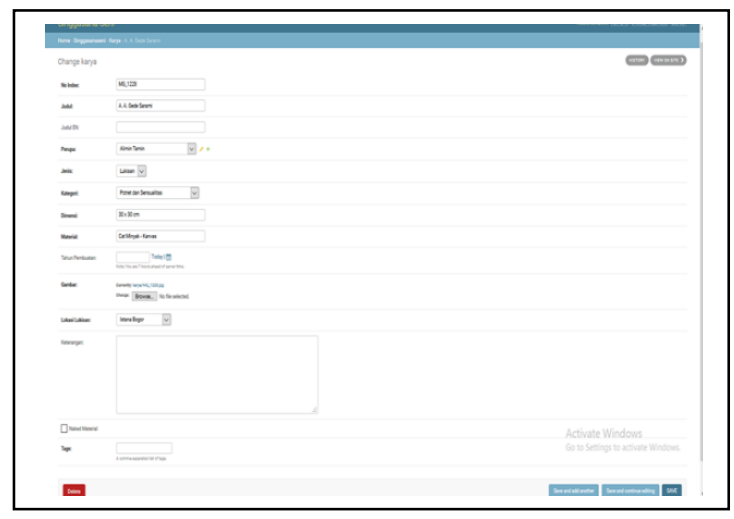

Gambar 5.Tampilan Form Ubah Data

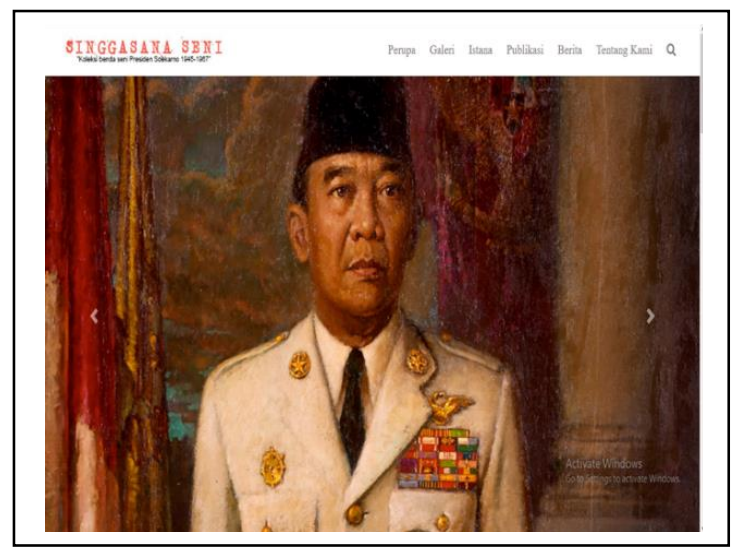

Gambar 6.Tampilan Halaman Beranda

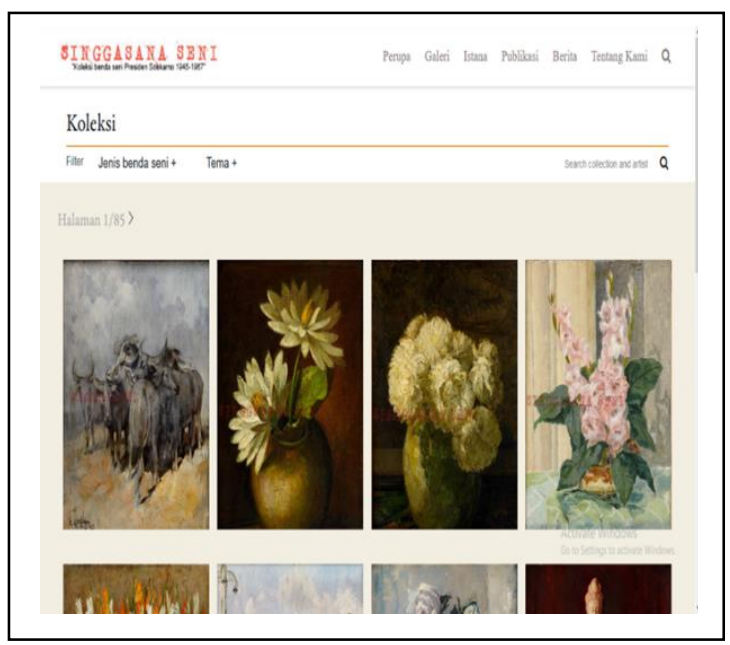

Gambar 7.Tampilan Koleksi Seni

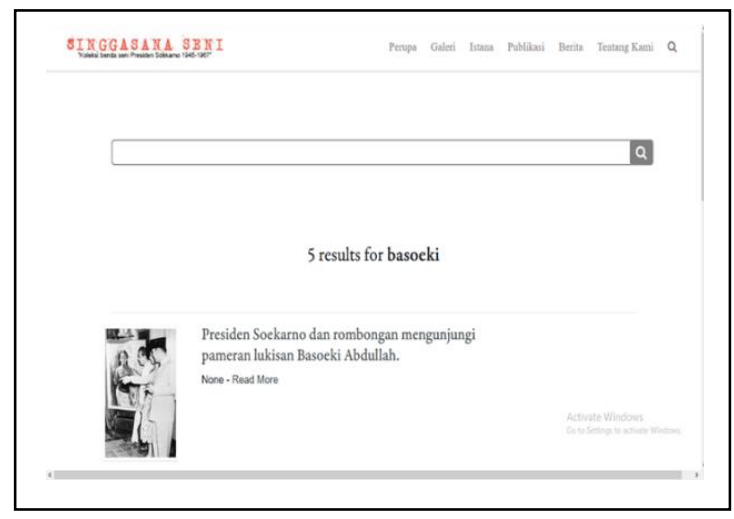

Gambar 8.Tampilan Halaman Pencarian

\section{Pengujian}

Pengujian merupakan proses yang dilakukan untuk tujuan mencari kesalahan, pengujian yang baik adalah pengujian yang memiliki kemungkinan besar dalam menemukan kesalahan.

Tahapan ini dilakukan pengujian black box untuk menguji apakah sistem yang di kembangkan sesuai dengan apa yang tertuang dalam spesifikasi fungsional sistem. Black Box juga digunakan untuk menguji fungsi-fungsi khusus dari perangkat lunak yang di rancang. Kebenaran perangkat lunak yang di uji hanya di lihat berdasarkan keluaran yang di hasilkan dari data atau kondisi masukan yang di berikan untuk fungsi yang ada tanpa melihat bagaimana proses untuk mendapatkan keluaran tersebut. Skenario pengujian berfungsikan untuk mengelompokan masingmasing sistem yang akan di uji.

Tabel 1. Tabel Pengujian Black Box Login

\begin{tabular}{|c|c|c|c|c|}
\hline No & $\begin{array}{l}\text { Deskripsi } \\
\text { Pengujian }\end{array}$ & $\begin{array}{l}\text { Hasil Yang } \\
\text { Diharapkan }\end{array}$ & $\begin{array}{c}\text { Hasil } \\
\text { Pengujian }\end{array}$ & Kesimpulan \\
\hline 1 & $\begin{array}{l}\text { Mengosongkan } \\
\text { username dan } \\
\text { langsung } \\
\text { menekan tombol } \\
\text { login. }\end{array}$ & $\begin{array}{l}\text { Sistem akan } \\
\text { menolak } \\
\text { akses login } \\
\text { dan akan } \\
\text { menampilkan } \\
\text { "pleasefill out } \\
\text { thisfield" }\end{array}$ & $\begin{array}{l}\text { Sistem dapat } \\
\text { menolak akses } \\
\text { login dan akan } \\
\text { menampilkan } \\
\text { "pleasefillout } \\
\text { this field" }\end{array}$ & valid \\
\hline 2 & $\begin{array}{l}\text { Mengosongkan } \\
\text { password dan } \\
\text { langsung } \\
\text { menekan tombol } \\
\text { login. }\end{array}$ & $\begin{array}{l}\text { Sistem akan } \\
\text { menolak } \\
\text { akses login } \\
\text { dan akan } \\
\text { menampilkan } \\
\text { "pleasefilloutt } \\
\text { hisfield" }\end{array}$ & $\begin{array}{l}\text { Sistem dapat } \\
\text { menolak akses } \\
\text { login dan akan } \\
\text { menampilkan } \\
\text { "pleasefilloutt } \\
\text { hisfield" }\end{array}$ & valid \\
\hline 3 & $\begin{array}{c}\text { Mengisi } \\
\text { username dan } \\
\text { password yang } \\
\text { salah dan klik } \\
\text { tombol login. }\end{array}$ & $\begin{array}{l}\text { Sistem akan } \\
\text { menolak } \\
\text { akses login } \\
\text { dan akan } \\
\text { menampilkan } \\
\text { "user tidak } \\
\text { ditemukan!" }\end{array}$ & $\begin{array}{c}\text { Sistem dapat } \\
\text { menolak akses } \\
\text { login dan akan } \\
\text { menampilkan } \\
\text { "user tidak } \\
\text { ditemukan!" }\end{array}$ & valid \\
\hline 4 & $\begin{array}{c}\text { Mengisi } \\
\text { username dan } \\
\text { password yang } \\
\text { benar dan } \\
\text { menekan tombol } \\
\text { login. }\end{array}$ & $\begin{array}{l}\text { Sistem akan } \\
\text { menampilkan } \\
\text { halaman }\end{array}$ & $\begin{array}{c}\text { Sistem dapat } \\
\text { menampilkan } \\
\text { halaman }\end{array}$ & valid \\
\hline
\end{tabular}


J|KI

Tabel 2. Tabel Pengujian Black Box Singgasanasseni_ Perupa

\begin{tabular}{|c|c|c|c|c|}
\hline No & $\begin{array}{l}\text { Deskripsi } \\
\text { Pengujian }\end{array}$ & $\begin{array}{c}\text { Hasil Yang } \\
\text { Diharapkan }\end{array}$ & $\begin{array}{c}\text { Hasil } \\
\text { Pengujian }\end{array}$ & Kesimpulan \\
\hline 1 & $\begin{array}{l}\text { User mengisi } \\
\text { form data } \\
\text { singgasanaseni } \\
\text { _perupa dengan } \\
\text { benar dan } \\
\text { menekan } \\
\text { tombol simpan }\end{array}$ & $\begin{array}{c}\text { Sistem akan } \\
\text { menampilka } \\
\mathrm{n} \text { data yang } \\
\text { dimasukan } \\
\text { kedalam } \\
\text { tabel }\end{array}$ & $\begin{array}{l}\text { Sistem dapat } \\
\text { menampilkan } \\
\text { data di dalam } \\
\text { tabel }\end{array}$ & valid \\
\hline 2 & $\begin{array}{c}\text { User } \\
\text { mengosongkan } \\
\text { form data } \\
\text { singgasanaseni } \\
\text { _perupa dan } \\
\text { menekan } \\
\text { tombol simpan }\end{array}$ & $\begin{array}{l}\text { Sistem akan } \\
\text { menolak dan } \\
\text { memberikan } \\
\text { keterangan } \\
\text { "pleasefillou } \\
\text { tthisfield" }\end{array}$ & $\begin{array}{l}\text { Sistem dapat } \\
\text { menolak dan } \\
\text { memberikan } \\
\text { keterangan } \\
\text { "pleasefillout } \\
\text { thisfield" }\end{array}$ & valid \\
\hline 3 & $\begin{array}{l}\text { User mengedit } \\
\text { data pada tabel } \\
\text { master data } \\
\text { singgasanaseni } \\
\text { _perupa }\end{array}$ & $\begin{array}{c}\text { Sistem } \\
\text { berhasil } \\
\text { mengedit } \\
\text { maka dalam } \\
\text { tabel data } \\
\text { singgasanas } \\
\text { eni_perupa } \\
\text { akan } \\
\text { berubah }\end{array}$ & $\begin{array}{c}\text { Sistem } \\
\text { berhasil } \\
\text { mengedit } \\
\text { maka dalam } \\
\text { tabel data } \\
\text { singgasanase } \\
\text { ni_perupa } \\
\text { dapat } \\
\text { berubah }\end{array}$ & valid \\
\hline 4 & $\begin{array}{c}\text { User } \\
\text { menghapus } \\
\text { data } \\
\text { singgasanaseni } \\
\text { _perupa pada } \\
\text { tabel master } \\
\text { data } \\
\text { singgasanaseni } \\
\text { _perupa }\end{array}$ & $\begin{array}{l}\text { Sistem akan } \\
\text { memberikan } \\
\text { peringatan } \\
\text { "anda yakin } \\
\text { ingin }\end{array}$ & $\begin{array}{l}\text { Sistem dapat } \\
\text { memberikan } \\
\text { keterangan } \\
\text { "anda yakin } \\
\text { ingin }\end{array}$ & valid \\
\hline
\end{tabular}

Tabel 3. Tabel Pengujian Black Box Singgasanasseni_ Karya

\begin{tabular}{|c|c|c|c|c|}
\hline No & $\begin{array}{l}\text { Deskripsi } \\
\text { Pengujian }\end{array}$ & $\begin{array}{c}\text { Hasil Yang } \\
\text { Diharapkan }\end{array}$ & $\begin{array}{c}\text { Hasil } \\
\text { Pengujian }\end{array}$ & Kesimpulan \\
\hline \begin{tabular}{|l|}
1 \\
\end{tabular} & $\begin{array}{l}\text { User mengisi } \\
\text { form data } \\
\text { singgasanaseni } \\
\text { _karya dengan } \\
\text { benar dan } \\
\text { menekan } \\
\text { tombol simpan }\end{array}$ & $\begin{array}{c}\text { Sistem akan } \\
\text { menampilka } \\
\mathrm{n} \text { data yang } \\
\text { dimasukan } \\
\text { ke dalam } \\
\text { tabel }\end{array}$ & $\begin{array}{c}\text { Sistem dapat } \\
\text { menampilkan } \\
\text { data di dalam } \\
\text { tabel }\end{array}$ & valid \\
\hline 2 & $\begin{array}{c}\text { User } \\
\text { mengosongkan } \\
\text { form data } \\
\text { singgasanaseni } \\
\text { karya } \\
\text { danmenekan } \\
\text { tombol simpan }\end{array}$ & $\begin{array}{c}\text { Sistem akan } \\
\text { menolak dan } \\
\text { memberikan } \\
\text { keterangan } \\
\text { "pleasefillou } \\
\text { tthisfield" }\end{array}$ & $\begin{array}{l}\text { Sistem dapat } \\
\text { menolak dan } \\
\text { memberikank } \\
\text { eterangan } \\
\text { "pleasefillout } \\
\text { thisfield" }\end{array}$ & valid \\
\hline 3 & $\begin{array}{c}\text { User mengedit } \\
\text { data pada tabel } \\
\text { master data } \\
\text { singgasanaseni } \\
\text { _karya }\end{array}$ & $\begin{array}{c}\text { Sistem } \\
\text { berhasil } \\
\text { mengedit } \\
\text { maka dalam } \\
\text { tabel data } \\
\text { singgasanas } \\
\text { eni_karya } \\
\text { akan } \\
\text { berubah }\end{array}$ & $\begin{array}{c}\text { Sistem } \\
\text { berhasil } \\
\text { mengedit } \\
\text { maka dalam } \\
\text { tabel data } \\
\text { singgasanase } \\
\text { ni_karya } \\
\text { dapat } \\
\text { berubah }\end{array}$ & valid \\
\hline 4 & $\begin{array}{c}\text { User } \\
\text { menghapus } \\
\text { data } \\
\text { singgasanaseni } \\
\text { _karya pada } \\
\text { tabel master } \\
\text { data } \\
\text { singgasanaseni } \\
\text { karya }\end{array}$ & $\begin{array}{c}\text { Sistem akan } \\
\text { memberikan } \\
\text { peringatan } \\
\text { "anda yakin } \\
\text { ingin }\end{array}$ & $\begin{array}{l}\text { Sistem dapat } \\
\text { memberikan } \\
\text { keterangan } \\
\text { "anda yakin } \\
\text { ingin }\end{array}$ & valid \\
\hline
\end{tabular}

\section{Kesimpulan}

Berdasarkan hasil penelitian di atas, maka kesimpulan dari penelitian ini adalah:

1. Penelitian ini menggunakan dua web dengan fungsi berbeda namun saling terkoneksi yaitu web untuk pengguna dan web untuk admin. $W e b$ untuk pengguna digunakan untuk mendapatkan informasi tentang karya seni yang terdapat pada istana negara dan web admin digunakan untuk mengelola data pada web Singgasana Seni.

2. Sistem informasi Singgasana Seni diharapkan dapat mempermudah akses masyarakat terhadap benda seni yang terbatas sehingga membuat pengetahuan masyarakat atas seni menjadi lebih baik.

Setelah melakukan perancangan sistem informasi Singgasana Seni berbasis web ini, beberapa saran yang harus diterapkan guna pengembangan sistem lebih lanjut, yakni:

1. Perlunya pengembangan dari segi fitur yang dimiliki seperti penambahan fitur berbagi (sharing) ke berbagai media sosial agar semakin banyak masyarakat yang mengetahui tentang seni.

2. Sistem ini dapat dikembangkan ke dalam versi mobile baik Android maupun IOS.

\section{Daftar Pustaka}

[1] Binus University. (2019). UML Diagram : Use Case Diagram. Dipetik Juni 4, 2020, dari School of Computer Science: https://socs.binus.ac.id/2019/11/26/umldiagram-use-case-diagram/

[2] Harminingtyas, R. (2014). Analisis Layanan Website sebagai Media Promosi, Media Transaksi dan Media Informasi dan Pengaruhnya terhadap Brand Image Perusahaan pada Hotel Ciputra di Kota Semarang. Jurnal STIE Semarang, 6(3), 3757.

[3] Husain, T. (2019). An Analysis of Modeling Audit Quality Measurement Based on Decision Support Systems (DSS). European Journal of Scientific Exploration, (6), 1-9.

[4] Husain, T., \& Budiyantara, A. (2018). Analisis End-User Computing Satisfaction (EUCS) Dan WebQual 4.0 Terhadap Kepuasan Pengguna. JATISI: Jurnal Teknik Informatika dan Sistem Informasi, 4(2), 164176.

[5] KBBI. (2020). kbbi.we.id/koleksi. Diambil kembali dari kbbi.web.id: https://kbbi.web.id/koleksi

[6] Kompasiana.com. (2020, Juni 9). Seni Media (Kebiasaan) Baru Kemajuan Teknologi Informasi dan Seni. Dipetik Juli 3, 2020, dari https://www.kompasiana.com/iiculyogya/54ff f4d38133111918fa6f05/seni-media- 

ЛIKI

kebiasaan-baru-kemajuan-teknologiinformasi-dan-seni

[7] Kusnendi. (2014). Modul 1: Konsep Dasar Sistem Informasi. Jakarta: Universitas Terbuka.

[8] Nusantoro, J., Rosid, A., \& Sudarmaji, S. (2019, December). Penerapan Transparansi Dan Akuntabilitas Penggunaan Dana Desa Melalui Sistem Laporan Keuangan Berbasis Web. In Seminar Nasional Pengabdian Kepada Masyarakat (Vol. 4, Pp. 126-131).

[9] Pratomo, Y. (2019, Mei 16). APJII: Jumlah Pengguna Internet di Indonesia Tembus 171 Juta Jiwa, Online. (O. Yusuf, Penyunting) Dipetik Januari 25, 2020, dari Kompas.com: https://tekno.kompas.com/read/2019/05/16/0 3260037/apjii-jumlah-pengguna-internet-diindonesia-tembus-171-juta-jiwa

[10] Pressman, R. S. (2012). Pendekatan Praktisi Rekayasa Perangkat Lunak (7 ed.). Yogyakarta: Penerbit ANDI.

[11] Rianto, P. (2014). Analisis Sistem Kearsipan pada UPT. Badan Perpustakaan Umum, Arsip dan Dokumentasi Kecamatan Siak Kecil Kabupaten Bengkalis. Riau: UIN Sultan Syarif Kasim.

[12] Saragih, d. A. (2015). Perancangan Aplikasi E-Library Menggunakan Bahasa Pemrograman PHP Pada Universitas Methodist Indonesia. 1.

[13] Sugiyono. (2016). Metode Penelitian Kombinasi (Mixed Methods). (M. Sutopo, Penyunt.) Bandung: CV. Alfabeta.

[14] Thabroni, G. (2020, 2 24). Konsep Seni: Pengertian, Sifat, Struktur, Fungsi \& Aplikasinya. Diambil kembali dari serupa.id: https://serupa.id/konsep-seni-dan-aplikasinya/

[15] Wikipedia. (2019, September 25). Istana Negara. Diambil kembali dari Wikipedia.com: https://id.wikipedia.org/wiki/Istana_Negara

[16] Yayasan Singgasana Seni. (2020). Diambil kembali dari http://singgasanaseni.org/

[17] Yusufhin, F. (2017). Peranan IVAA (Indonesian Visual Art Archieve) Dalam Pengembangan Seni di Yogyakarta. Yogyakarta: UIN Sunan Kalijaga.

[18]Zailani, A. U., Perdananto, A., \& Sholihin, N. (2020). Pengenalan Sejak Dini Siswa SMP tentang Machine Learning untuk Klasifikasi Gambar dalam Menghadapi Revolusi 4.0. KOMMAS: Jurnal Pengabdian Kepada Masyarakat, 1(1), 7-15. 